\title{
Stage IV Childhood Hepatocellular Carcinoma AJCC v7
}

National Cancer Institute

\section{Source}

National Cancer Institute. Stage IV Childhood Hepatocellular Carcinoma A/CC v7. NCI

Thesaurus. Code C7838.

Stage IV includes: IVA: (Any T, N1, M0); IVB: (Any T, Any N, M1). N1: Regional lymph node metastasis. M0: No distant metastasis. M1: Distant metastasis. (AJCC 7th ed.) 